\title{
EVALUATION OF HER2/neU EXPRESSION IN OVARIAN EPITHELIAL TUMOURS
}

\author{
Arya P. $R^{1}$, Sheela Varghese ${ }^{2}$, Sankar $S^{3}$ \\ 1Postgraduate Student, Department of Pathology, Government Medical College, Kottayam, Kerala. \\ ${ }^{2}$ Associate Professor, Department of Pathology, Government Medical College, Kottayam, Kerala. \\ 3Professor and HOD, Department of Pathology, Government Medical College, Kottayam, Kerala.
}

\section{BACKGROUND}

\section{ABSTRACT}

Ovarian cancers are most lethal of all gynaecological malignancies and becoming a leading cause of death due to malignancy in female. This may be attributed to its late clinical presentation and poor response to current treatment modalities. Many targeted treatment modalities are under intense clinical trials. One such approach is based on the demonstration of HER-2/neu overexpression. According to literatures, HER-2/neu expression varies widely in ovarian epithelial tumours.

This study was conducted to describe the expression of HER-2/neu in different types of ovarian epithelial tumours using a scoring system and to identify the proportion of cases with HER-2/neu positivity in benign, borderline and malignant ovarian epithelial tumours.

\section{MATERIALS AND METHODS}

A descriptive study was conducted to assess HER-2/neu immunoreactivity in 91 cases of ovarian surface epithelial tumours received in the Department of Pathology, Government Medical College, Kottayam during a period of 18 months (April 2016 September 2017).

\begin{abstract}
RESULTS
Of the 91 ovarian surface epithelial tumours studied 52 were benign (57.1\%), 6 were borderline (6.6\%) and 33 were malignant (36.3\%). Among the malignant tumours, serous malignancies were the largest group with 19 cases (57.6\%) followed by 9 mucinous carcinomas (27.3\%), 3 clear cell carcinomas (9.1\%), 1 malignant Brenner (3\%) and 1 seromucinous carcinoma (3\%). IHC with HER-2/neu was done in all the 91 cases, which showed score 0 in $54.9 \%$, score $1+$ in $25.3 \%$, score $2+$ in $16.5 \%$ and score $3+$ in 3.3\%. All benign and borderline cases were HER-2/neu negative. Among 33 ovarian malignancies, 9.1\% were HER-2/neu positive (Score 3+). Among the mucinous carcinomas, 33.3\% showed significant overexpression of HER-2/neu. All other histological types were negative ( $p$ value $<0.05$ ). There was no statistical association between HER-2/neu positivity and other clinico-pathological parameters such as age, presence of ascites, CA-125, size and stage of the ovarian tumours ( $p$ value $>0.05$ ).
\end{abstract}

\section{CONCLUSION}

Mucinous carcinomas are associated with significant overexpression of HER-2/neu, hence trastuzumab would be a treatment option for patients with mucinous carcinoma showing HER-2/neu overexpression.

\section{KEY WORDS}

HER-2/Neu; Mucinous Carcinoma; Trastuzumab.

HOW TO CITE THIS ARTICLE: Arya PR, Varghese S, Sankar S. Evaluation of HER2/neu expression in ovarian epithelial tumours. J. Evolution Med. Dent. Sci. 2018;7(15):1883-1887, DOI: 10.14260/jemds/2018/424

\section{BACKGROUND}

Ovarian cancers are most lethal of all gynaecological malignancies. They constitute $3 \%$ of malignancies in female. There are about 204,000 new cases and 125,000 deaths annually.

The latest WHO statistics reveal that ovarian cancers are as frequent as corpus uteri cancer (35\%) and invasive cervical cancer $(27 \%)$. Nearly, $70 \%$ of women with ovarian cancer die of this disease. The vague and non-specific clinical symptoms have contributed to the delayed detection of the tumour after it has undergone extensive spread and metastasis. The prognosis is considered poor even with extensive research and advances in treatment modalities.

'Financial or Other Competing Interest': None.

Submission 26-01-2018, Peer Review 22-03-2018,

Acceptance 28-03-2018, Published 09-04-2018.

Corresponding Author:

Dr. Sheela Varghese,

Associate Professor, Department of Pathology,

Government Medical College, Kottayam-686008, Kerala.

E-mail: dr.sheelavarghese@gmail.com

DOI: $10.14260 /$ jemds $/ 2018 / 424$
Immunohistochemistry has become a pivotal diagnostic tool for ovarian cancers.

HER-2 (Human Epidermal Growth Factor Receptor-2) also termed as HER-2/neu is a proto-oncogene that encodes a protein belonging to EGFR tyrosine kinase receptor family. HER-2 overexpression initiates intracellular signaling pathways involved in cell proliferation, differentiation, migration and apoptosis. HER-2/neu positivity is considered as an indicator of poor prognosis in breast cancer and has a positive correlation with aggressive disease, shortened disease-free interval and overall survival. In patients having metastatic breast cancer with HER-2/neu overexpression or amplification, a combination therapy of humanised anti-HER2 monoclonal antibody (Trastuzumab) and a taxane with or without carboplatin has been found to be highly effective.

Perusal of literature reveals that HER-2/neu overexpression/amplification in ovarian tumours had a wide range (between $8 \%$ and 66\%) and it might be associated with chemo resistance and poor outcome. Hence, treatment with trastuzumab (Targeted therapy) may improve patient outcome in such cases, which show HER-2/neu overexpression. 


\section{Objectives}

1. To describe the expression of HER-2/neu in different types of Ovarian Surface Epithelial Tumours using a scoring system.

2. To identify the proportion of cases with HER-2/neu positivity in benign, borderline and malignant ovarian epithelial tumours.

\section{MATERIALS AND METHODS \\ Type of Study}

A descriptive study.

\section{Period of Study}

18 months (April 2016 - September 2017).

\section{Study Setting}

Department of Pathology, Government Medical College, Kottayam.

\section{Study Population}

Biopsy specimens of ovarian epithelial tumours received in the Department of Pathology during the study period.

\section{Sample Size}

Sample size $\mathrm{N}=4 \mathrm{pq} / \mathrm{d}^{2}$

$\mathrm{p}=$ prevalence/ proportion in previous study, $\mathrm{q}=100-\mathrm{p}$

$\mathrm{d}=$ precision/ allowable error

Proportion of HER-2/neu positivity among epithelial tumours in a study by Sarkar et al was 35\%, q= $1-p=65$

Taking absolute precision as 10

Sample size, $N=\underline{4 p q}=\frac{4 \times 35 \times 65}{d^{2}}=91$

Hence, sample size is taken as 91 .

\section{Sampling Method}

Study sample include first 91 cases of ovarian epithelial tumours received in the Department of Pathology, Government Medical College, Kottayam during the study period.

\section{Inclusion Criteria}

Histopathologically diagnosed cases of different types of surface epithelial tumours of ovary in Department of Pathology at Kottayam Medical College will be included.

\section{Exclusion Criteria}

Cases without proper data, cases with differential diagnosis, non-neoplastic lesions and non-epithelial tumours of ovary, metastatic lesions and post-neoadjuvant therapy specimens will be excluded.

\section{Study Procedure}

Clinical details of each case will be recorded first along with investigation results. Gross examination of the specimen will be done. Tumour size will be measured in three dimensions and the largest dimension will be taken into account. Appropriate bits of tissues representative of areas to be studied will be taken. All specimens will be fixed in formalin and embedded in paraffin. 4 microns thick sections will be stained with $\mathrm{H}$ and $\mathrm{E}$ for routine histological examination.
Immunohistochemical staining will be done after a proper histopathological diagnosis and is performed on representative bits of the tumour using rabbit monoclonal HER-2/neu antibody.

Immunoreactivity will be graded according to the distribution and intensity of staining. Score 0 - No stain or faint incomplete membrane stain in not more than $10 \%$ cells, $1+-$ Weak and incomplete membrane staining in more than $10 \%$ of the tumour surface, $2+-$ Complete intense membrane staining in not more than $10 \%$ of the invasive tumour cells or weak/moderate heterogeneous incomplete staining in more than $10 \%$ of the invasive tumour cells and $3+-$ Strong complete homogeneous membrane staining in more than $10 \%$ of the invasive tumour cells. Positive control- HER-2/neu positive breast carcinoma tissue, negative control - normal ovarian tissue.

\section{Data Management and Analysis}

The data was entered in Microsoft Excel and further statistical analysis was done using SPSS software (Version 20). The statistical methods used were mean, frequency, proportion and non-parametric test (chi-square test). The level of significance was indicated as ' $p$ ' value $<0.05$.

\section{RESULTS}

- The mean age of ovarian surface epithelial tumours was 45.64 years.

- $\quad$ Of the 91 ovarian surface epithelial tumours studied, 52 were benign $(57.1 \%), 6$ were borderline $(6.6 \%)$ and 33 were malignant (36.3\%).

- Benign and borderline tumours formed the majority of cases below 45 years. Malignancies accounted for $30.3 \%$ of the cases below 45 years, but increased to $69.7 \%$ of the cases above 45 years.

- Serous tumours formed the majority with $59.3 \%$ followed by $35.2 \%$ mucinous tumours, $3.3 \%$ clear cell carcinomas, $1.1 \%$ malignant Brenner tumour and 1.1\% seromucinous carcinoma.

- Among the serous tumours $59.2 \%$ were benign, $5.6 \%$ were borderline and $35.2 \%$ were malignant. Among the mucinous tumours $62.5 \%$ were benign, $9.4 \%$ were borderline and $28.1 \%$ were malignant. There were 3 clear cell carcinomas, 1 malignant Brenner and 1 seromucinous carcinoma.

- Among the malignant tumours, serous malignancies were the largest group with 19 cases (57.6\%) followed by 9 mucinous carcinomas (27.3\%), 3 clear cell carcinomas (9.1\%), 1 malignant Brenner (3\%) and 1 seromucinous carcinoma (3\%).

- Ascites was present in 57.6\% malignant cases, in which high-grade serous carcinomas predominated.

- CA-125 was found to be elevated only in 21 cases (23.1\%), of which $90.5 \%$ were malignant.

- IHC with HER-2/neu was done in all the 91 cases which showed score 0 in $54.9 \%$, score $1+$ in $25.3 \%$, score $2+$ in $16.5 \%$ and score $3+$ in $3.3 \%$.

- All benign and borderline cases were HER-2/neu negative. Among 33 ovarian malignancies, 9.1\% were HER-2/neu positive (Score $3+$ ). This association of HER$2 /$ neu positivity among malignant and non-malignant (benign and borderline) was found to be statistically 
significant by chi-square test with a chi-square value of 5.45 and a 'p' value of 0.02 .

- Among the mucinous carcinomas, $33.3 \%$ showed significant overexpression of HER-2/neu. All other histological types were negative $(\mathrm{P}$ value $<0.05)$. This association of HER-2/neu positivity among mucinous carcinomas and non-mucinous carcinomas was found to be statistically significant by chi-square test with a chisquare value of 8.80 and a 'p' value of $0.003(<0.05)$.

- There was no statistical association between HER-2/neu positivity and other clinico-pathological parameters such as age, presence of ascites, CA-125, size and stage of the ovarian tumours ( $\mathrm{p}$ value $>0.05$ ).

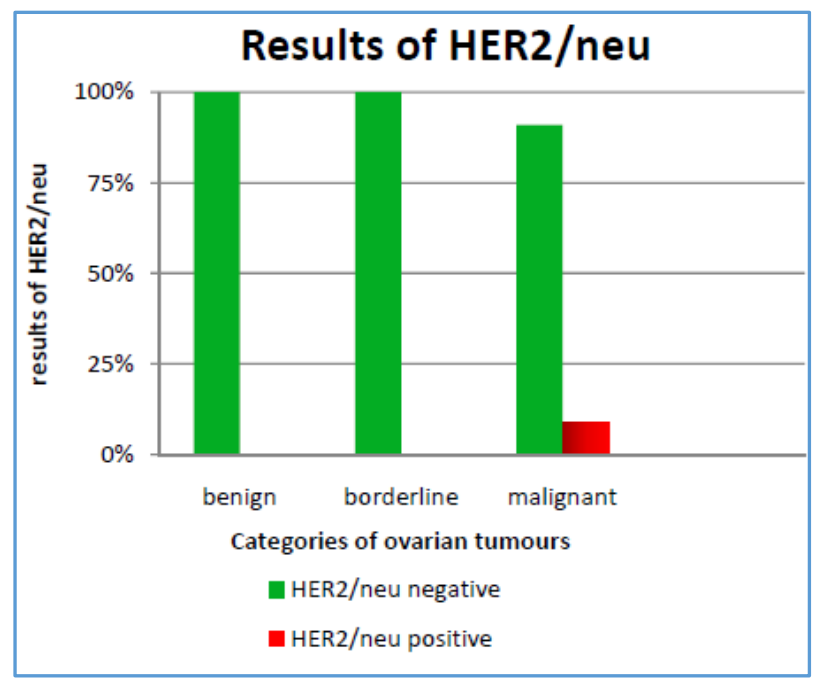

Figure 1. HER-2/neu Positivity in Benign, Borderline and Malignant Tumours

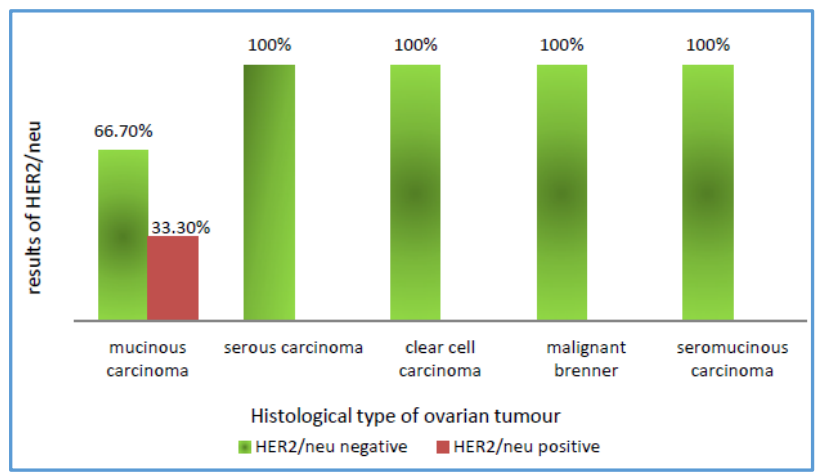

Figure 2. HER-2/neu Positivity among various Histological Types of Malignancies

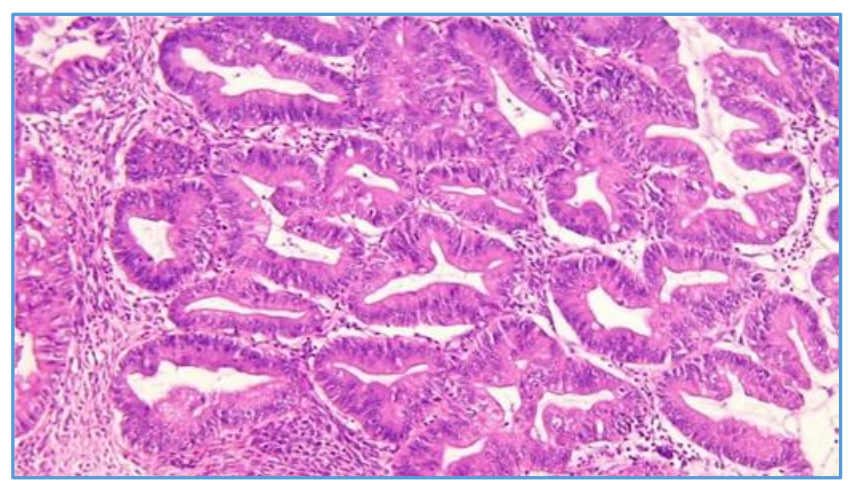

Figure 3. Photomicrograph of Mucinous Carcinoma (10X) $H$ and $E$ Stain

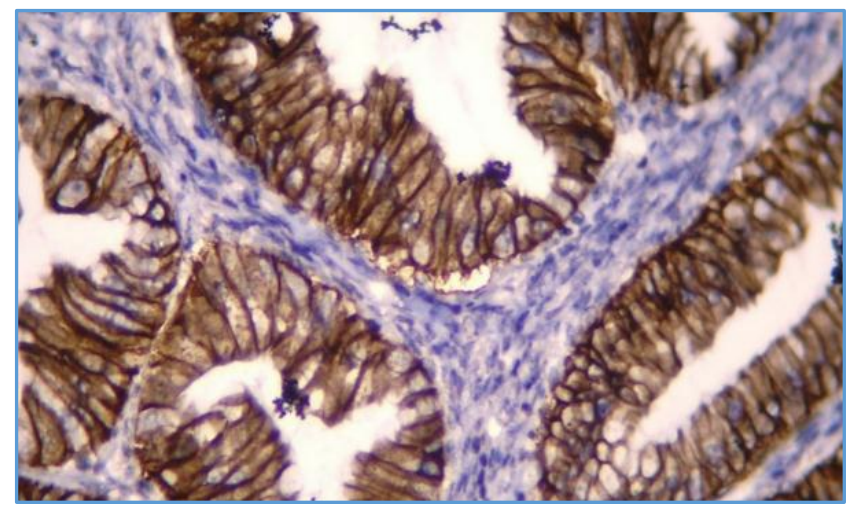

Figure 4. Mucinous Carcinoma- HER-2/neu Score 3+ Strong Diffuse Membrane Staining (40X)

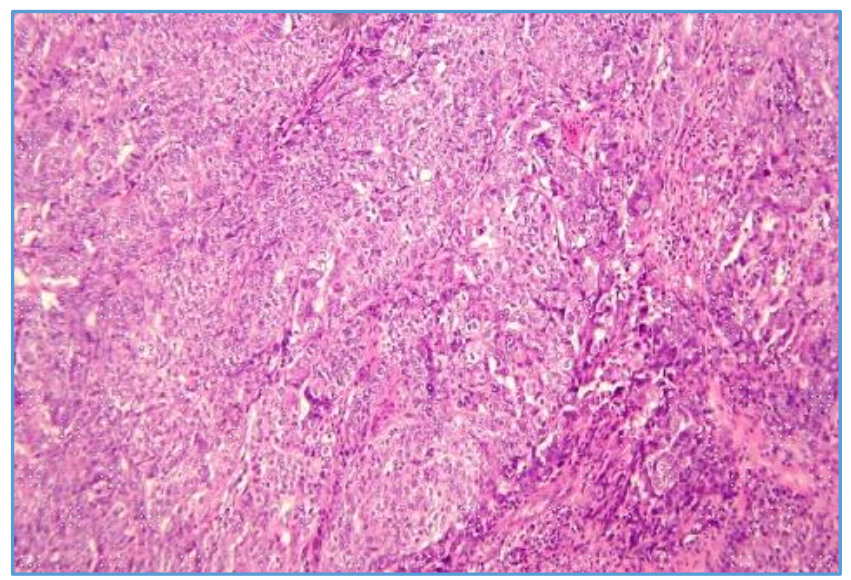

Figure 5. Serous Carcinoma H and E (10X)

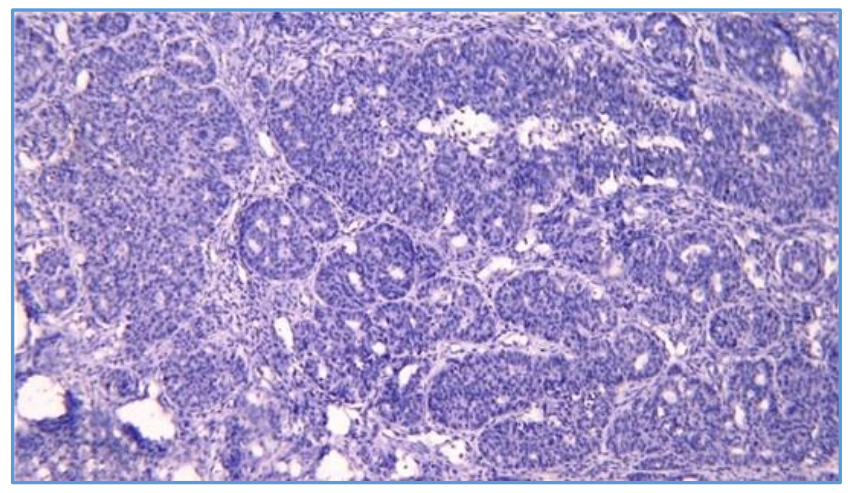

Figure 6. Serous Carcinoma HER-2/neu Negative

\section{DISCUSSION}

Ovarian malignancies are becoming one of the leading causes of death in women. This is attributed to its late clinical presentation and poor response to current treatment modalities. Many targeted treatment modalities are under intense clinical trials for the use in ovarian cancers because of the heterogeneity of this disease and its poor response to treatment. One such approach is based on the demonstration of HER-2/neu overexpression, which is associated with resistance to platinum-based chemotherapy and poor survival. But the rate of HER-2/neu expression varies widely in literature ranging from $8 \%$ to $66 \%$. The role of this marker in ovarian cancers is not yet clear with contradicting results and conflicting data. Thus, the prognostic influence of HER$2 /$ neu is still a matter of debate.

The present study was conducted in 91 cases of ovarian surface epithelial tumours received in the Department of 
Pathology, Government Medical College, Kottayam during April 2016 to September 2017, in which HER-2/neu expression was assessed.

The mean age of ovarian surface epithelial tumours in the present study was 45.64 years, which is comparable with study conducted by Sarkar et al ${ }^{1}$ in 2015 done in 68 cases of epithelial ovarian tumours, which showed a mean age of 41.03 years.

Histopathological analysis of the 91 cases of ovarian surface epithelial tumours 52 were benign (57.1\%), 6 were borderline (6.6\%) and 33 were malignant (36.3\%). These findings are comparable with studies done by Sarkar et $\mathrm{al}^{1}$ and Goel S et al. ${ }^{2}$

Serous tumours formed the majority with $59.3 \%$ followed by $35.2 \%$ mucinous tumours, $3.3 \%$ clear cell carcinomas, $1.1 \%$ malignant Brenner tumour and 1.1\% seromucinous carcinoma. These findings were comparable with studies by Sarkar et al $^{1}$ and Sylvia et al. ${ }^{3}$ Table 1: Comparison of frequencies of histopathological types with other studies.

\begin{tabular}{|c|c|c|c|}
\hline & $\begin{array}{c}\text { Present } \\
\text { Study }\end{array}$ & $\begin{array}{c}\text { Sarkar } \\
\text { et al1 }\end{array}$ & $\begin{array}{c}\text { Sylvia } \\
\text { et al3 }\end{array}$ \\
\hline Serous & $59.3 \%$ & $58.8 \%$ & $53.3 \%$ \\
\hline Mucinous & $35.2 \%$ & $36.8 \%$ & $28.3 \%$ \\
\hline Clear cell & $3.3 \%$ & 0 & $1.6 \%$ \\
\hline Brenner & $1.1 \%$ & $1.4 \%$ & $1.6 \%$ \\
\hline Endometrioid & $1.1 \%$ & $1.4 \%$ & $6.7 \%$ \\
\hline Others/Mixed & 0 & $1.4 \%$ & $8.3 \%$ \\
\hline Total & $\mathbf{4 0 0 \%}$ & $\mathbf{1 0 0 \%}$ & $\mathbf{1 0 0 \%}$ \\
\hline \multicolumn{4}{|c|}{ Table 1 } \\
\hline
\end{tabular}

In the present study, among the various malignant tumours, serous malignancies formed the largest group with $57.6 \%$ followed by mucinous carcinomas (27.3\%), clear cell carcinomas (9.1\%), malignant Brenner (3\%) and seromucinous carcinoma (3\%). These findings are comparable with study by Sarkar et al, which also demonstrated serous malignancy predominance with $70 \%$ followed by mucinous $20 \%$, Brenner $5 \%$ and others $5 \%$.

None of the benign or borderline tumours had ascites in the present study. Among the 33 malignant cases 19 cases (57.6\%) had ascites, predominantly in high-grade serous carcinomas $(73.7 \%)$. This is comparable with the study by Ruchika Garg et al, ${ }^{4}$ in which $40.9 \%$ of malignant tumours had ascites.

Immunohistochemical staining with HER-2/neu was done in all 91 cases of ovarian surface epithelial tumours and scoring was done based on the modified ASCO/CAP guidelines. In the present study, among the 91 cases 50 showed score 0 (54.9\%), 23 scored $1+(25.3 \%), 15$ scored $2+$ $(16.5 \%)$ and 3 scored $3+(3.3 \%)$. Considering score $3+$ as HER-2/neu positivity (overexpression), all benign and borderline cases were HER-2/neu negative. Among 33 malignant cases, $9.1 \%$ were HER-2/neu positive and the remaining $90.9 \%$ were negative. This is compared with other studies by Steffensen et al, ${ }^{5}$ Fujimura et $\mathrm{al}^{6}$ and Sarkar et $\mathrm{al}^{1}$ which showed a positivity of $9.1 \%, 4.4 \%$ and $28.8 \%$ respectively.

In the present study, only mucinous carcinomas showed significant overexpression of HER-2/neu (33.3\%) and all other histological types showed HER-2/neu negativity. This is compared with previous studies by McCaughan et $\mathrm{al}^{7}$ and Fujimura et al. ${ }^{6}$

\begin{tabular}{|c|c|c|c|}
\hline $\begin{array}{c}\text { Histological } \\
\text { Type }\end{array}$ & $\begin{array}{c}\text { Present } \\
\text { Study }\end{array}$ & $\begin{array}{c}\text { McCaughan } \\
\text { et al7 }\end{array}$ & $\begin{array}{c}\text { Fujimura } \\
\text { et al6 }\end{array}$ \\
\hline Serous & 0 & $3 \%(3 / 259)$ & $\begin{array}{c}20.8 \% \\
(11 / 53)\end{array}$ \\
\hline Mucinous & $33.3 \%(3 / 9)$ & $25 \%(3 / 12)$ & $30 \%(3 / 10)$ \\
\hline Clear cell & 0 & $4 \%(1 / 25)$ & $\begin{array}{c}42.9 \% \\
(15 / 35)\end{array}$ \\
\hline Brenner & 0 & 0 & 0 \\
\hline Mixed & 0 & $11.9 \%(7 / 60)$ & 0 \\
\hline Table 2. Comparison of HER-2/neu Positivity in various \\
Histological Types of Malignancies \\
\hline \multicolumn{4}{|c}{} \\
\hline
\end{tabular}

In the present study, 33.3\% HER-2/neu positivity was observed among mucinous carcinomas, which was found to be statistically significant with a ' $p$ ' value $<0.05$. This is comparable with the study conducted by Yan et al, who reported $35.3 \%$ positivity in mucinous carcinoma. The results of other studies by Anglesio et al (18.8\%), McCaughan et al (18.2\%) and McAlpine et al (18.2\%) also goes in concordance with the current result.

\begin{tabular}{|c|c|}
\hline & HER-2/neu Positivity \\
\hline Present Study $^{-}$ & $33.3 \%$ \\
\hline Yan et al $^{8}$ & $35.3 \%$ \\
\hline${\text { Fujimura et } \mathrm{al}^{6}}^{6}$ & $30 \%$ \\
\hline${\text { McCaughan et } \mathrm{al}^{7}}$ & $25 \%$ \\
\hline McAlpine et al $^{9}$ & $18.2 \%$ \\
\hline Table 3. Comparison of HER-2/neu Positivity in Mucinous \\
Carcinoma \\
\hline
\end{tabular}

In the present study, all of the serous carcinomas (19/19) showed HER-2/neu negativity. This finding is in contrast with study by Sarkar et al, who reported that HER-2/neu expression was more intense for high-grade advanced stage serous carcinomas and was found in $35 \%$ serous carcinomas. Results of other studies including those by Fujimura et al (20.8\%) and McCaughan et al (3\%) also go against the results of the present study. This difference may be due to- (1) Difference in antibody type used, (2) Technical problems in antigen retrieval, (3) Unavailability of FISH to confirm equivocal score of 2+ and (4) Variation in IHC interpretation.

HER-2/neu expression in other histopathological types of EOC studies regarding HER-2/neu expression in other histopathological types of EOC are very few in the literature. In the present study all other types of EOC (Clear cell carcinomas, malignant Brenner and seromucinous carcinoma) were negative for HER-2/neu. Previous studies by Fujimura et al and McCaughan et al also reported the same result in case of Brenner tumour, but with regard to clear cell carcinoma they found $42.9 \%$ and $4 \%$ positivity respectively. This difference may be due to small sample size and technical problems in antigen retrieval and association of HER-2/neu positivity with other clinico-pathological parameters.

In the present study, even though there was significant overexpression of HER-2/neu noted in mucinous carcinomas, this result showed no statistical association with clinicopathological parameters such as age, presence of ascites, CA125 , size and stage of the ovarian tumours ( $p$ value $>0.05$ ).

\section{Limitations of the Present Study}

- Small sample size 
- Unavailability of FISH to evaluate equivocal score in IHC (score 2+). Short study period and inability to follow-up the cases.

\section{CONCLUSION}

The objectives of the study are concluded as follows:

- Epithelial ovarian carcinomas were associated with HER$2 /$ neu overexpression. All benign and borderline tumours were HER-2/neu negative.

- Mucinous carcinoma was the only histological subtype, which showed significant overexpression of HER-2/neu within the study group.

Thus, based on the findings of present study, it is suggested that trastuzumab along with current chemotherapy would be an option for patients with mucinous carcinoma showing HER-2/neu overexpression, since these carcinomas are associated with poor response with current chemotherapy alone.

\section{REFERENCES}

[1] Sarkar M, Jha T, Das TK, et al. Spectrum of epithelial ovarian tumors with HER2/neu expression by the carcinomas among patients admitted in a tertiary care hospital in Eastern India. Int J Med Sci Public Health 2015;4(10):1388-92.

[2] Goel S, Mehra M, Yadav A, et al. A comparative study of HER-2/neu oncogene in benign and malignant ovarian tumors. International Journal of Scientific Study 2014;2(4):50-4.
[3] Sylvia MT, Kumar S, Dasari P. The expression of immunohistochemical markers estrogen receptor, progesterone receptor, Her-2-neu, p53 and Ki-67 in epithelial ovarian tumors and its correlation with clinicopathologic variables. Indian J Pathol Microbiol 2012;55(1):33-7.

[4] Garg R, Singh S, Rani R, et al. A clinicopathological study of malignant ovarian tumors in India. JSAFOMS 2014;2(1):9-11.

[5] Steffensen KD, Waldstrom M, Jeppesen U, et al. The prognostic importance of cyclooxygenase 2 and HER2 expression in epithelial ovarian cancer. Int J Gynecol Cancer 2007;17(4):798-807.

[6] Fujimura M, Katsumata N, Tsuda H, et al. HER2 Is frequently over-expressed in ovarian clear cell adenocarcinoma: possible novel treatment modality using recombinant monoclonal antibody against HER2, trastuzumab. Jpn J Cancer Res 2002;93(11):1250-7.

[7] McCaughan H, Um I, Langdon SP, et al. HER2 expression in ovarian carcinoma: caution and complexity in biomarker analysis. J Clin Pathol 2012;65(7):670-1.

[8] Yan B, Choo SN, Mulyadi P, et al. Dual-colour HER2/chromosome 17 chromogenic in situ hybridisation enables accurate assessment of HER2 genomic status in ovarian tumours. J Clin Pathol 2011;64(12):1097-101.

[9] McAlpine JN, Wiegand KC, Vang R, et al. HER2 overexpression and amplification is present in a subset of ovarian mucinous carcinomas and can be targeted with trastuzumab therapy. BMC Cancer 2009;9:433. 